\title{
Pengembangan Aplikasi Pupuh Sunda Berbasis Android Menggunakan Intel XDK
}

\section{Pupuh Sunda Android-based Application Development Using Intel XDK}

\author{
Fitri Nuraeni*1, Susanto $^{2}$, Dani Kustiawan ${ }^{3}$ \\ 1,2,3 Jurusan Teknik Informatika, STMIK Tasikmalaya \\ 1․ㅡenk.ufit@gmail.com, ${ }^{2}$ susantosobatbumi@gmail.com, ${ }^{3}$ dani.kustiawan@gmail.com
}

\begin{abstract}
Abstrak
Kebudayaan di Indonesia sangat beragam dimana setiap provinsi memiliki kebudayaan masingmasing yang beraneka ragam. Salah satunya yaitu Pupuh Sunda yang berasal dari Jawa Barat. Pupuh merupakan karya sastra berbentuk puisi yang termasuk bagian dari sastra Sunda. Namun seiring dengan perkembangan zaman dengan teknologi yang berkembang dengan pesat, perlahan pupuh Sunda mulai terlupakan. Melihat maraknya penggunaan smartphone Android saat ini, maka hal tersebut dapat menjadi peluang untuk mengenalkan kembali pupuh Sunda melalui media aplikasi pupuh Sunda berbasis Android. Maka dirancang aplikasi pupuh Sunda berbasis Android menggunakan metode prototyping dengan pendekatan berorientasi objek. Perangkat lunak yang digunakan untuk membangun aplikasi pupuh Sunda ini yaitu Intel XDK yang merupakan IDE cross-platform yang berbasis pada teknologi web (HTML5, CSS, dan JavaScript). Untuk mengetahui kemampuan dari aplikasi Pupuh Sunda yang telah dibangun, maka dilakukan kuesioner pada 22 orang siswa yang terdiri dari 8 orang siswa SMP/Sederajat, dan 14 orang siswa SMA/Sederajat. Dari kuesioner ini didapatkan bahwa aplikasi Pupuh Sunda yang dikembangkan mendapatkan nilai total 378 dari 440 nilai maksimal yang bisa didapatkan. Sedangkan aplikasi Pupuh Sunda yang terdapat di Google Play Store mendapat nilai total 266 dari 440 nilai yang bisa didapatkan. Artinya aplikasi Pupuh Sunda hasil penelitian ini sudah lebih baik dari aplikasi Pupuh Sunda yang terdapat di Google Play Store.
\end{abstract}

Kata kunci - Android, Pupuh, Sunda, Intel XDK

\begin{abstract}
Culture in Indonesia is very diverse, that province in Indonesia has the culture of each different culture in other areas. One culture that Indonesia is Pupuh Sunda. Pupuh is a work of literature is poetry that included part of Sundanese literature. But along with the times with technology evolving rapidly, slowly Pupuh Sunda began to be forgotten. With the widespread use of android smartphones, it is expected to be one of the solutions to reintroduce Pupuh Sunda via Pupuh Sunda media applications based on Android. Pupuh Sunda Android-based applications are designed using prototyping methods with object oriented approach. The software used to build applications Pupuh Sunda namely Intel XDK, is an IDE cross-platform based on web technologies (HTML5, CSS, and JavaScript). To determine the ability of Pupuh Sunda applications that have been built, then conducted a questionnaire on 22 students consisting of eight junior high students/ equivalent, and 14 high school student/ equal. Of the questionnaire showed that applications Pupuh Sunda developed by finds the total 378 from 440 the maximum value that can be obtained. While the application Pupuh Sunda contained in the Google Play Store gets a total value of 266 of the 440 value that can be obtained. This means that applications Pupuh Sunda developed by Author has been better than Pupuh Sunda applications contained in the Google Play Store.
\end{abstract}

Keywords - Android, Pupuh, Sunda, Intel XDK 


\section{PENDAHULUAN}

Kebudayaan di Indonesia sangat beragam dimana provinsi di Indonesia memiliki kebudayaan masing-masing yang berbeda dengan kebudayaan di daerah lain. Suku Sunda adalah salah satu dari berbagai macam suku yang ada di Indonesia yang merupakan etnis terbesar kedua setelah Jawa[1]. Sekurang-kurangnya 15,2\% penduduk Indonesia merupakan orang Sunda. Jika Suku Banten dikategorikan sebagai sub suku Sunda maka 17,8\% penduduk Indonesia merupakan orang Sunda.

Suku Sunda juga memiliki kebudayaan khas yang berbeda dengan kebudayaan suku lain di Indonesia. Budaya Sunda adalah budaya yang tumbuh dan hidup dalam masyarakat Sunda. Budaya Sunda dikenal dengan budaya yang sangat menjunjung tinggi sopan santun. Pada umumnya karakter masyarakat Sunda adalah periang, ramah-tamah (soméah, seperti dalam falsafah someah hade ka semah), murah senyum, lemah-lembut, dan sangat menghormati orang tua. Itulah cermin budaya masyarakat Sunda.

Salah satu kebudayaan Sunda yang populer lainnya adalah Pupuh. Pupuh merupakan karya sastra berbentuk puisi yang termasuk bagian dari sastra Sunda. Pupuh ialah pola lirik yang terikat pada beberapa patokan (aturan) yang berupa guru wilangan, guru lagu, pedotan dan watek, yang di adopsi dari kesenian Jawa, yaitu macapat[2]. Dalam pupuh, yang disebut juga dangding, memiliki aturan jumlah suku kata atau engang dalam satu baris disebut guru wilangan[3]. Setiap larik atau baris disebut pada atau padalisan atau guru gatra. Ada pun permainan lagu berupa bunyi vokal akhir di tiap padalisan disebut guru lagu. Secara harfiah, pupuh bisa diartikan sebagai bait atau pada. Pupuh tidak hanya dikenal di Sunda, namun juga di Jawa, Bali, Madura, dan Lombok.

Namun seiring dengan kencangnya laju globalisasi sebagai konsekuensi logis dari perkembangan ilmu pengetahuan dan teknologi, hal tersebut memberikan pengaruh positif bagi kemajuan dan membawa dampak negatif pada saat yang bersamaan. Seperti pemberitaan dari Pikiran Rakyat online yang menyatakan bahwa krisis kebudayaan ditengarai lahir dari ketidaksiapan masyarakat menerima globalisasi[4]. Bukan sekedar itu, perubahan yang dikhawatirkan adalah perubahan yang bertentangan dengan nilai-nilai kultur kesundaan. Dampak negatif yang dapat dirasakan saat ini yaitu pupuh semakin ditinggalkan dan tergerus budaya luar. Untuk dapat menghindari punahnya pupuh Sunda maka kita harus melestarikan dan mengenalkannya kembali kepada masyarakat etnis Sunda itu sendiri.

Mengingat begitu pesatnya perkembangan dan penggunaan teknologi belakangan ini maka upaya yang dilakukan juga harus memanfaatkan teknologi yang banyak digunakan oleh masyarakat secara umum. Salah satu produk teknologi yang saat ini banyak digunakan adalah smartphone. Hampir semua orang memiliki perangkat ini, terlebih lagi smartphone yang menggunakan Android. Android adalah sebuah sistem operasi open source berbasis Linux yang dibuat dan dikelola oleh sebuah grup yang terdiri dari perusahaan software dan hardware serta operator yang disebut Open Handset Alliance[3]. Pada smartphone Android ini terdapat sebuah toko aplikasi yang bernama Google Play Store yang berisi aplikasi-aplikasi Android seperti game, media player, instant messanger, dan lain sebagainya.

Salah satu aplikasi yang terdapat pada Google Play Store adalah Pupuh Sunda yang dipublish oleh SeamolecApps dengan kategori Pendidikan. Aplikasi ini dibuat untuk mempermudah pengguna dalam mempelajari pupuh sunda. Tentu aplikasi ini sangat membantu menyelesaikan permasalahan yang terjadi di mana pupuh sunda ini semakin tergerus budaya luar. Keberadaan aplikasi ini sangat disambut positif oleh pengguna. Terlihat dari banyaknya komentar positif yang menyatakan bahwa aplikasi ini bagus dan bahkan ada yang mencari-cari aplikasi pupuh yang baru menemukan aplikasi Pupuh Sunda di Play Store. Namun ada komentar yang mengkritik tentang kualitas suara pada aplikasi ini harus diganti dengan kualitas yang lebih baik. Setelah dilakukan percobaan terhadap aplikasi Pupuh Sunda tersebut memang didapatkan bahwa kualitas suara yang keluar terasa kurang baik. 
Pupuh Bali yang berasalh dari Pulau Bali telah memiliki aplikasi berbasis android yang digunakan untuk melestarikan budaya bangsa tersebut[5]. Fitur-fitur dalam aplikasi ini bertujuan sebagai media belajar pupuh bagi pengguna dengan menggunakan perangkat Android. Adapun fitur dari aplikasi ini yaitu teori pupuh, uger-uger pupuh, laras pupuh, tembang pupuh dan rekaman pengguna. Selain itu, terdapat juga aplikasi android lain untuk nyanyian pupuh Bali yang memiliki empat fungsionalitas utama yakni pengenalan pupuh, menjawab quiz, membuat lirik, dan merekam pupuh[6].

Melihat kemampuan dari aplikasi Pupuh Bali di atas kemudian dibandingkan dengan aplikasi Pupuh Sunda yang ada di Play Store, maka perlu dilakukan pengembangan terhadap aplikasi pupuh sunda tersebut sebagai salah satu upaya pelestarian pupuh Sunda. Maka dibangunlah aplikasi pupuh sunda untuk mengembangkan aplikasi yang sudah ada dengan menggunakan Intel XDK. Kelebihan dari Intel XDK yaitu IDE ini bersifat cross platform di mana dari source code yang sama dapat menghasilkan output aplikasi yang berbeda. Intel XDK adalah sebuah development kit yang dibuat oleh Intel untuk membuat aplikasi native menggunakan teknologi web seperti HTML5, CSS, dan JavaScript[7].

Maka dihasilkan aplikasi pupuh sunda berbasis android dengan kualitas suara yang bagus dan fitur berupa macam-macam lirik untuk setiap pupuh dan kuis pengetahuan mengenai tiap-tiap jenis Pupuh Sunda. Dengan adanya aplikasi pupuh sunda ini dapat membantu melestarikan dan mengenalkan kembali Pupuh Sunda kepada masyarakat etnis Sunda dengan mudah hanya menggunakan perangkat smartphone saja.

\section{METODE PENELITIAN}

Model pengembangan rekayasa perangkat lunak yang digunakan adalah model pengembangan prototypingdengan pendekatan berorientasi objek. Prototyping adalah proses iteratif dalam pengembangan sistem di mana kebutuhan diubah ke dalam sistem yang bekerja (working system) yang secara terus menerus diperbaiki melalui kerjasama antara pengguna dan analis[8].

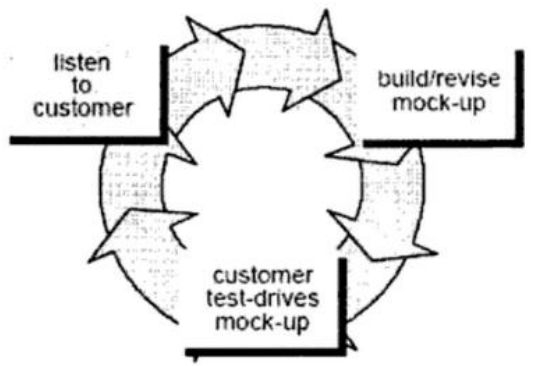

Gambar 1 Model Pengembangan Prototyping[8]

yaitu:

Tahap-tahap utama dari model ini memetakan kegiatan-kegiatan pengembangan dasar

1. Analis bekerja dengan tim untuk mengidentifikasi kebutuhan awal untuk sistem.

2. Analis kemudian membangun prototype. Ketika sebuah prototype sudah selesai, pengguna bekerja dengan prototype itu dan menyampaikan analis apa yang mereka sukai dan yang tidak mereka sukai.

3. Analis kemudian menggunakan feedback ini untuk memperbaiki prototype.

4. Versi baru diberikan kembali pada pengguna.

5. Ulangi langkah-langkah tersebut sampai pengguna merasa puas. 
Pemodelan dalam perancangan sistem menggunakan Unified Modelling Language (UML). Unified Modelling Language (UML) adalah sebuah "bahasa" yg telah menjadi standar dalam industri untuk visualisasi, merancang dan mendokumentasikan sistem piranti lunak[9].UML menawarkan sebuah standar untuk merancang model sebuah sistem.

Metode pengujian Black Box Testing adalah salah satu metode pengujian aplikasi yang mana kita tidak perlu tahu apa yang sesungguhnya terjadi dalam aplikasi atau perangkat lunak hanya mengamati keluaran dari berbagai masukkan[10]. Pengujian Black Box Testing terdiri dari Usability Test dan User Statisfaction yang akan mengidentifikasi kesalahan dalam beberapa kategori, yang mana diantaranya, kesalahan interface, fungsi-fungsi yang salah atau hilang, kesalahan pada struktur data ataupun akses database eksternal, kesalahan inisialisasi serta terminasi dan lainnya.

\section{HASIL DAN PEMBAHASAN}

Proses pengembangan aplikasi diawal dengan melakukan proses analisis. Dengan mengamati aplikasi pupuh sunda yang sudah ada sebelumnya, maka didapatkan kebutuhan fungsional yaitu mengenai fitur-fitur apa saja yang akan diterapkan pada aplikasi ini. Fitur- fitur tersebut antara lain :

1. Menampilkan halaman teori tentang pupuh.

2. Menampilkan patokan yang terdapat pada setiap pupuh.

3. Memiliki audio player beserta control bar sehingga pengguna dapat melakukan play, pause, skip, dan mute.

4. Menampilkan lirik dari pupuh yang dapat diputar di audio player dan juga menampilkan lirik alternatif dari pupuh tersebut.

5. Memiliki kuis guna menguji pengetahuan pengguna tentang pupuh Sunda.

Setelah proses analisis maka dilanjutkan dengan proses perancangan menggunakan

UML berupa Use Case Diagram, Skenario Use Case Diagram dan Activity Diagram.

Use case diagram merupakan alat untuk menggambarkan fungsionalitas yang diharapkan dari sebuah sistem. Yang ditekankan adalah "apa" yang diperbuat sistem, dan bukan "bagaimana". Sebuah use case merepresentasikan sebuah interaksi antara aktor dengan sistem. Pada gambar 2, digambarkan bahwa aplikasi pupuh sunda berbasis android ini memiliki 7 use case, yaitu sebagai berikut :

a) use case membaca tentang pupuh yaitu penjelasan mengenai pupuh sunda;

b) use case membaca patokan pupuh yaitu informasi mengenai guru lagu dan guru wilangan tiap-tiap jenis pupuh sunda;

c) use case mendengarkan pupuh dan membaca lirik yaitu fitur utama dimana pengguna dapat memutar file mp3 tiap pupuh sambil membaca lirik-lirik tiap pupuh;

d) use case mengerjakan kuis merupakan fitur tambahan untuk mengetes sejauh mana pengetahuan pengguna mengenai pupuh sunda

e) use case membagikan ke twitter merupakan use case yang include pada use case point d).

f) Use case bantuan adalah fitur yang menjelaskan bagaimana cara menggunakan aplikasi ini.

g) Use case tentang hanyalah informasi mengenai aplikasi ini dan pembuatnya. 


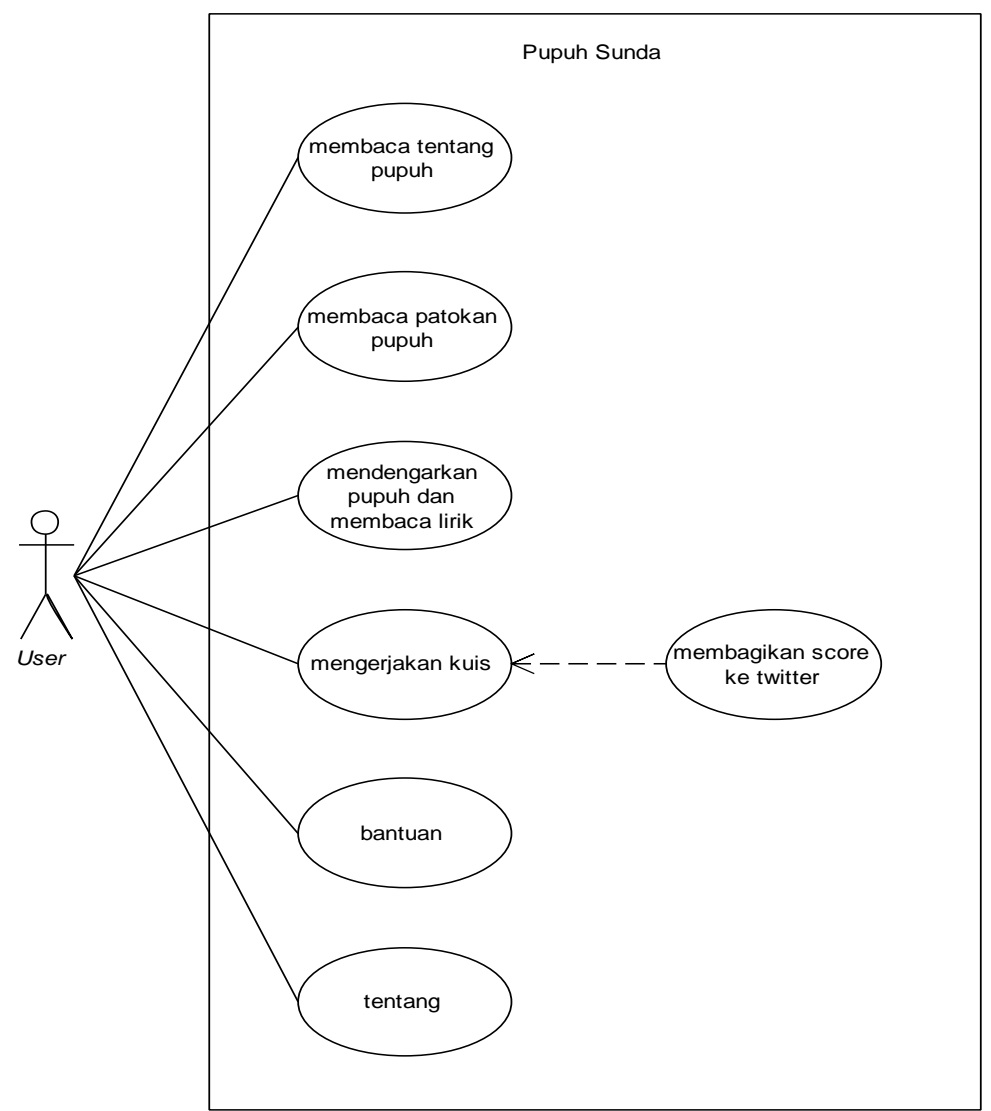

Gambar 2 use case diagram aplikasi pupuh sunda berbasis android

Untuk menjelaskan use case maka dibuatkanlah skenario use case. Pada bagian ini, hanya dibahas beberapa use case saja. Seperti pada tabel 1 dijabarkan rancangan fitur teori yang akan menampilkan informasi lengkap jenis pupuh sunda yang dipilih pengguna.

Tabel 1 skenario use case tentang teori

\begin{tabular}{|c|c|}
\hline Nama & Tentang Pupuh \\
\hline Tujuan & Untuk membaca tentang pupuh \\
\hline Aktor & User \\
\hline Deskripsi & $\begin{array}{l}\text { Meliputi proses } \\
\text { menggambarkan saat user akan } \\
\text { membaca teori tentang pupuh Sunda }\end{array}$ \\
\hline \multicolumn{2}{|r|}{ Skenario Utama } \\
\hline User & Sistem \\
\hline \multicolumn{2}{|l|}{$\begin{array}{l}\text { 1. } \begin{array}{l}\text { User membuka } \\
\text { aplikasi Pupuh } \\
\text { Sunda }\end{array} \\
\end{array}$} \\
\hline & $\begin{array}{l}\text { 2. Sistem menampilkan tampilan } \\
\text { menu utama }\end{array}$ \\
\hline \multirow[t]{2}{*}{$\begin{array}{l}\text { 3. Memilih menu } \\
\text { "Teori" }\end{array}$} & \\
\hline & 4. Menampilan menu "Teori" \\
\hline $\begin{array}{l}\text { 5. Membaca teori } \\
\text { tentang pupuh }\end{array}$ & \\
\hline
\end{tabular}


Sedangkan pada tabel 2, dijelaskan mengenai use case mendengarkan pupuh dan membaca lirik yang merupakan fitur utama dari aplikasi ini.

Tabel 2 skenario use case mendengarkan pupuh dan membaca lirik

\begin{tabular}{|c|c|}
\hline Nama & Mendengarkan Pupuh \\
\hline Tujuan & $\begin{array}{l}\text { Untuk mendengarkan pupuh dan membaca lirik dari pupuh yang } \\
\text { dipilih }\end{array}$ \\
\hline Aktor & User \\
\hline Deskripsi & $\begin{array}{l}\text { Meliputi proses yang menggambarkan saat user akan } \\
\text { mendengarkan pupuh dan membaca lirik dari pupuh yang dipilih }\end{array}$ \\
\hline & Skenario Utama \\
\hline User & Sistem \\
\hline $\begin{array}{l}\text { 1. User membuka aplikasi } \\
\text { Pupuh Sunda }\end{array}$ & \\
\hline & 2. Sistem menampilkan tampilan menu utama \\
\hline 3. Memilih menu "Tembang" & \\
\hline & 4. Menampilan menu "Tembang" \\
\hline $\begin{array}{l}\text { 5. Memilih pupuh. Misal } \\
\text { memilih pupuh Kinanti }\end{array}$ & \\
\hline & $\begin{array}{l}\text { 6. Menampilkan halaman pupuh kinanti (audio player dan } \\
\text { tampilan lirik) }\end{array}$ \\
\hline $\begin{array}{l}\text { 7. Mendengarkan pupuh Kinanti } \\
\text { dan membaca lirik }\end{array}$ & \\
\hline
\end{tabular}

Activity diagram merupakan state diagram khusus, di mana sebagian besar state adalah action dan sebagian besar transisi di-trigger oleh selesainya state sebelumnya (internal processing). Oleh karena itu activity diagram tidak menggambarkan behaviour internal sebuah sistem (dan interaksi antar subsistem) secara eksak, tetapi lebih menggambarkan proses-proses dan jalur-jalur aktivitas dari level atas secara umum.

Setiap aktivitas yang ada pada aplikasi ini digambarkan menggunakan diagram aktifitas seperti pada gambar 3 yang menjelaskan fitur teori pupuh. Untuk mengunakan fasilitas teori pupuh, user dapat memilih menu teori di menu utama kemudian sistem akan menampilkan informasi lengkap mengenai pupuh sunda dan jenis-jenisnya.

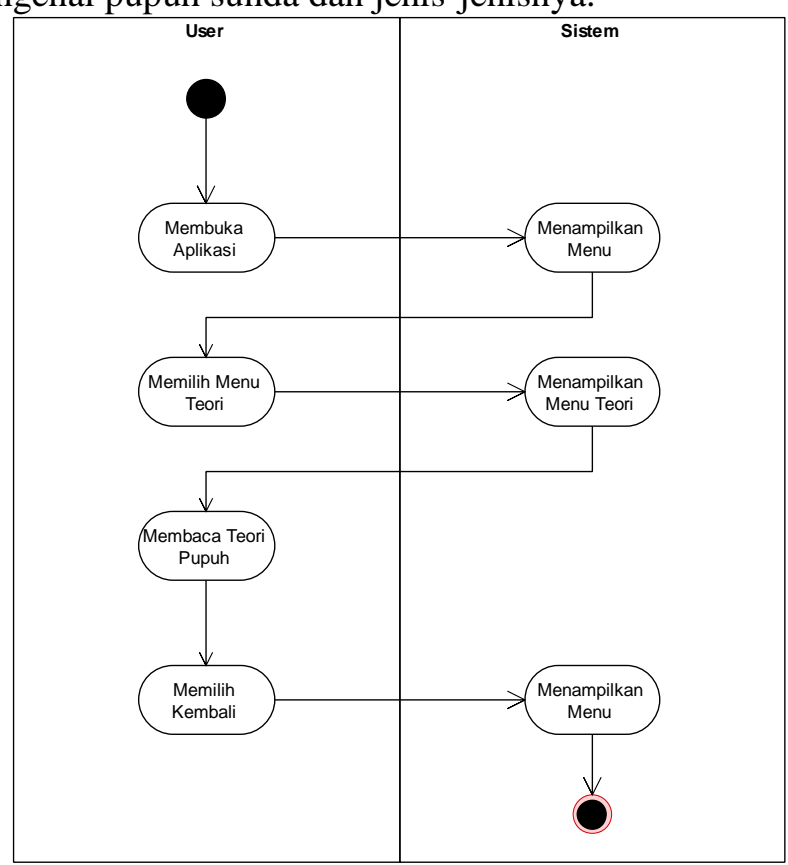

Gambar 3 activity diagram teori pupuh 
Gambar 4 yang menjelaskan fitur utama aplikasi ini yaitu mendengarkan pupuh. Untuk mendengarkan pupuh, pengguna harus memilih menu Pupuh di menu utama kemudian memilih jenis pupuh apa yang akan diputar. Selanjutnya sistem akan memainkan file mp3 dari pupuh yang sudah dipilih dan menampilkan deretan lirik untuk pupuh tersebut.

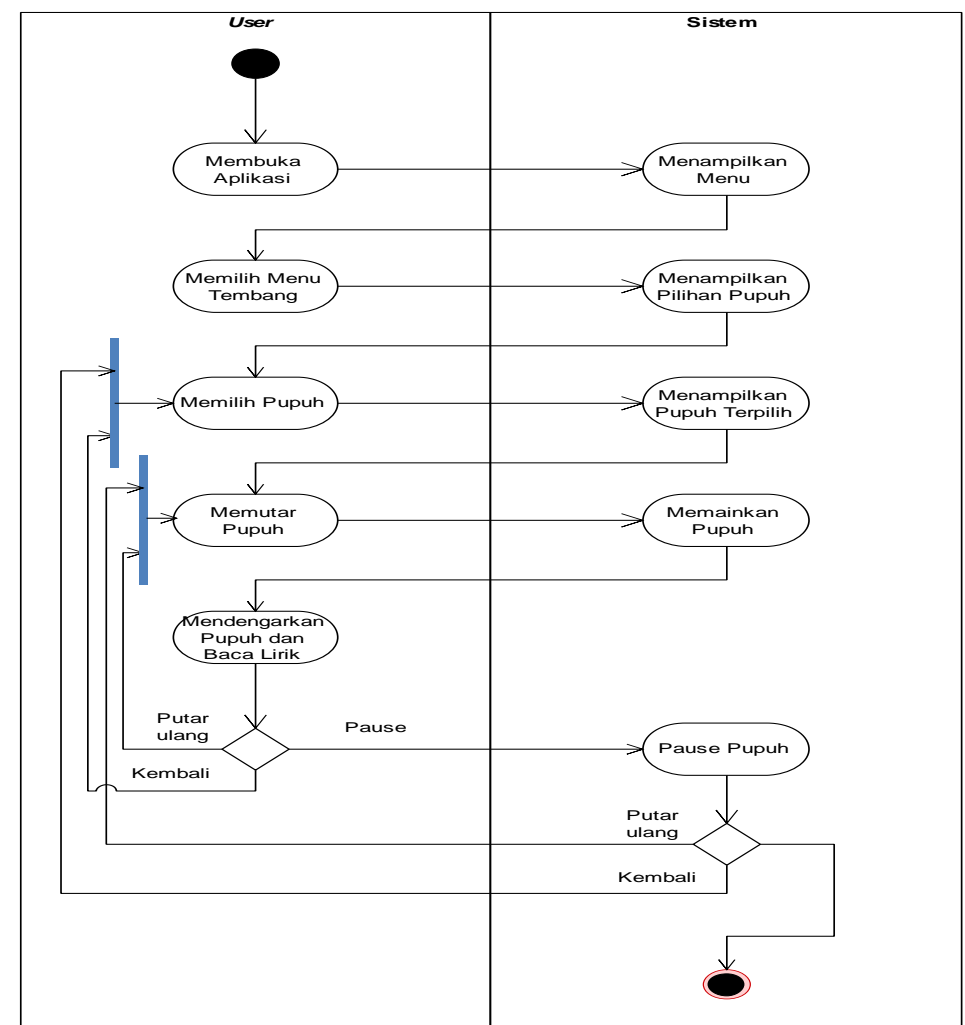

Gambar 4 activity diagram mendengarkan pupuh

Setelah proses perancangan selesai maka dilanjutkan dengan tahapan pembuatan aplikasi menggunaka Intel XDK. Aplikasi ini dimulai pada halaman menu utama, selanjutnya pengguna dapat memilih salah satu menu sesuai kebutuhan. Layout untuk menu utama ini dapat dilihat pada gambar 5, dimana terdapat lima buah tombol pada menu utama, yaitu menu Teori, menu Patokan, menu Tembang, menu Bantuan dan menu Tentang.

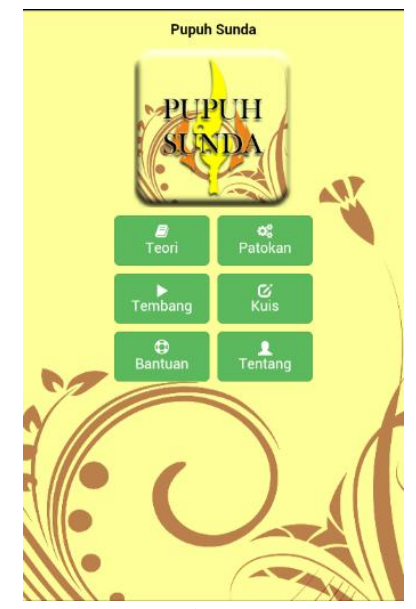

Gambar 5 Implementasi Antarmuka Menu Utama 
1. Tombol Menu Teori, tombol ini digunakan untuk mengakses halaman teori yang berisikan segala sesuatu tentang pupuh Sunda seperti pada gambar 6 .

2. Tombol Menu Patokan, berfungsi untuk mengakses halaman patokan pupuh, namun sebelumnya user harus memilih pupuh tertentu lalu sistem akan menampilkan patokan dari pupuh tersebut.

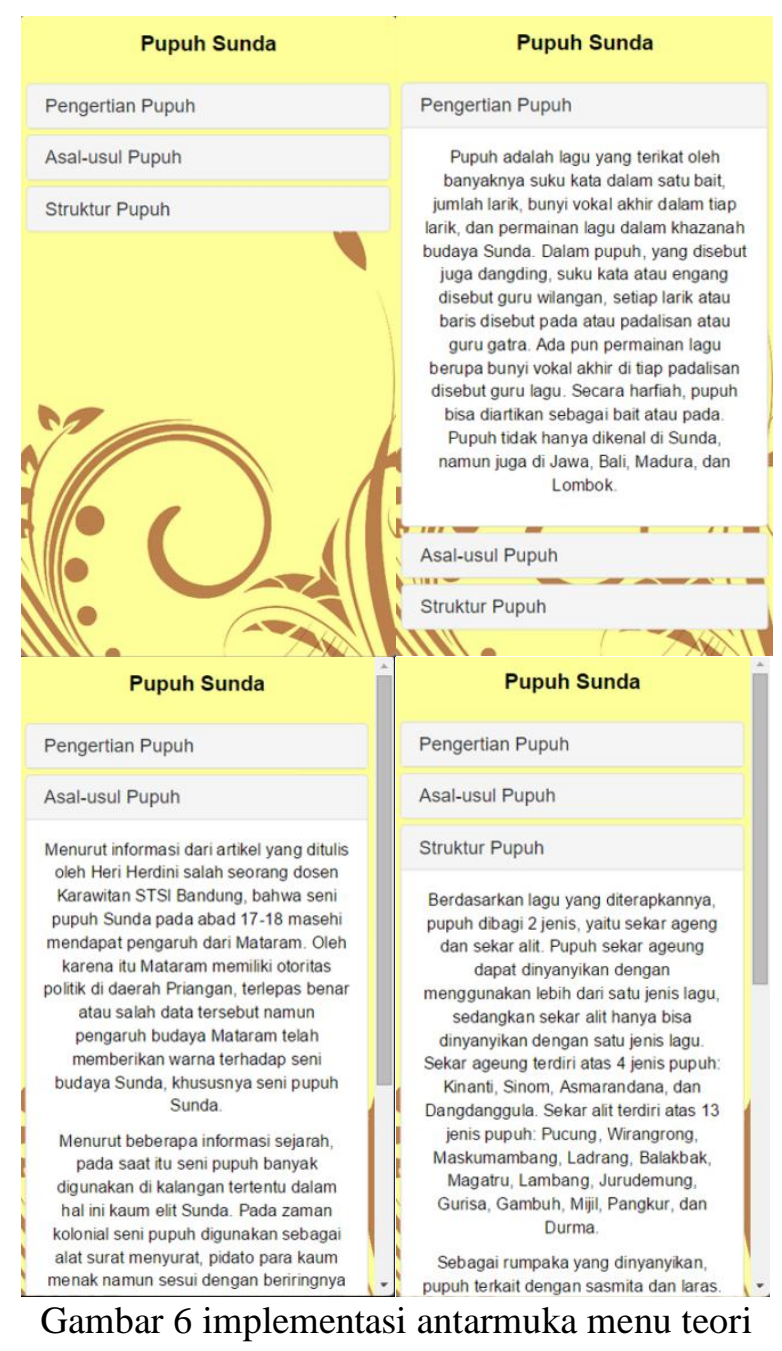

3. Tombol Menu Tembang, tombol ini digunakan untuk mengakses halaman tembang yang berisi audio player dan lirik dari pupuh seperti pada gambar 7. User juga diharuskan untuk memilih salah satu pupuh dan sistem akan menampilkan halaman pupuh yang dipilih.

4. Tombol Menu Bantuan, digunakan untuk mengakses halaman bantuan yang berguna untuk memberikan petunjuk kepada user cara menggunakan aplikasi.

5. Tombol Menu Tentang, digunakan untuk mengakses halaman tentang. Halaman tentang berisi informasi tentang aplikasi dan developer. 


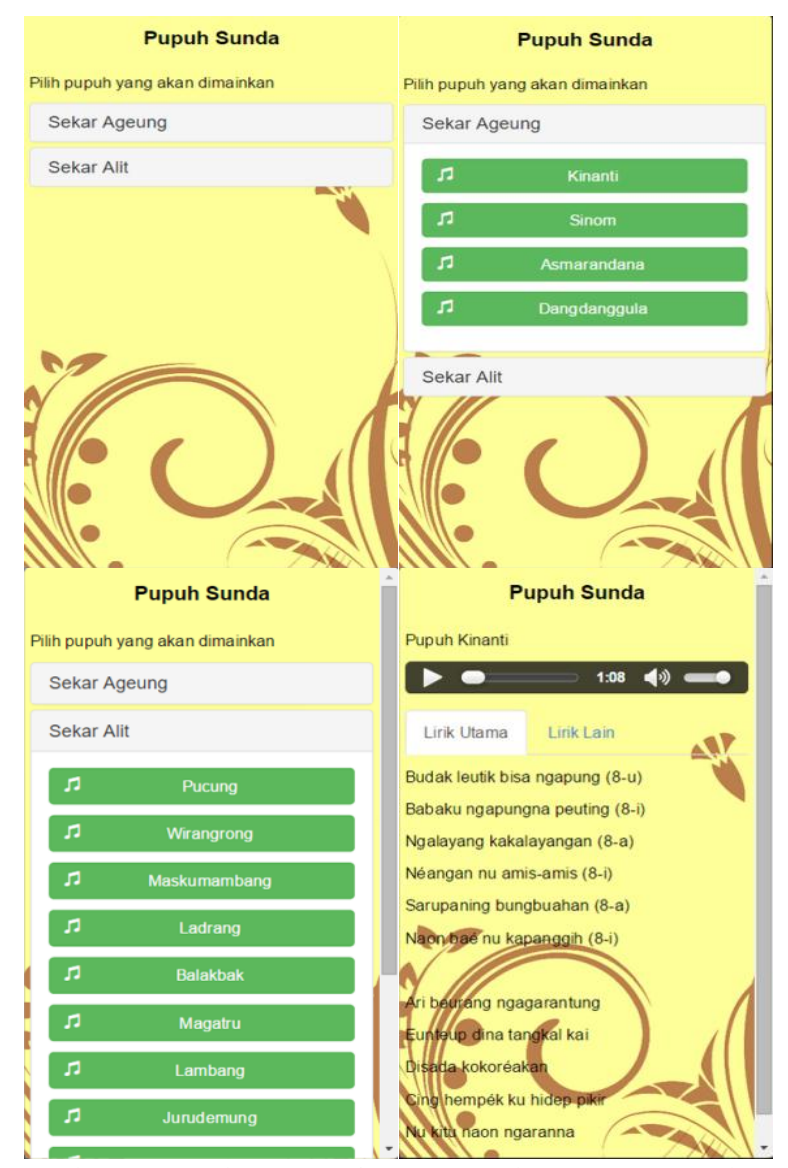

Gambar 7 Implementasi Antarmuka Menu Tembang

Sebelum program ini diimplementasikan, maka dibutuhkan proses pengujian. Dimana setiap fitur yang ada pada aplikasi diuji menggunakan metode black box seperti pada tabel 3 .

Tabel 3 Proses Pengujian

\begin{tabular}{llc}
\hline Kelas Uji & Objek Uji & Jenis Pengujian \\
\hline Teori & Teori & Blackbox \\
\hline Patokan & 17 Pupuh & Blackbox \\
\hline Tembang & 17 Pupuh & Blackbox \\
\hline Kuis & Kuis & Blackbox \\
\hline Bantuan & Bantuan & Blackbox \\
\hline Tentang & Tentang & Blackbox \\
\hline
\end{tabular}

Sample untuk proses pengujian halaman teori pupuh, dimana pengujian dilakukan 3 kondisi yaitu:

a) Collapse Pengertian Pupuh dipilih, diharapkan Collapse terbuka dan menampilkan teks, sedangkan collapse lain tertutup dan hasilnya berhasil sehingga pengujian dianggap sukses;

b) Collapse Asal-usul Pupuh dipilih, diharapkan Collapse terbuka dan menampilkan teks, sedangkan collapse lain tertutup dan hasilnya berhasil sehingga pengujian disimpulkan sukses;

c) Collapse Struktur Pupuh dipilih, diharapkan Collapse terbuka dan menampilkan teks, sedangkan collapse lain tertutup, hasilnya berhasil dan sukses.

Pengujian untuk menu Pupuh diambil sample pupuh sekar ageung dan jenis pupuh kinanti memiliki hasil :

a) Collapse Sekar Ageung, diharapkan Collapse terbuka dan menampilkan tombol-tombol, sedangkan collapse lain tertutup, dan hasil pengujian berhasil; 
b) Tombol Kinanti dipilih, diharapkan masuk ke halaman tembang pupuh Kinanti dan hasilnya berhasil;

c) Tombol Play diklik, diharapkan aplikasi memutar pupuh Kinanti dan hasilnya berhasil;

d) Tombol Pause diklik, diharapkan aplikasi menghentikan pemutaran pupuh Kinanti dan berhasil;

e) Runtime lagu digeser, diharapkan lagu loncat sesuai dengan pergeseran pada runtime, dan berhasil;

f) Icon volume diklik, diharapkan aplikasi menjadi mute/unmute dan berhasil;

g) Volume Control digeser, diharapkan level volume menjadi seperti pada volume control, dan berhasil;

h) Tab Lirik Lain diklik, diharapkan tab lirik berpindah pada tab Lirik Lain dan menampilkan lirik yang berbeda, hasilnya berhasil

i) Tab Lirik Utama diklik, diharapkan tab lirik berpindah pada tab Lirik Utama dan menampilkan lirik yang sesuai dengan lagu, dan berhasil.

Setelah dilakukan pengujian sesuai dengan rencana di atas didapatkan hasil bahwa semua fitur yang ada pada aplikasi Pupuh Sunda berjalan dengan baik sesuai dengan apa yang diharapkan.

Sedangkan untuk mengetahui pendapat pengguna terhadap aplikasi Pupuh Sunda yang telah dikembangkan pada penelitian ini, maka dilakukan kuesioner. Sasaran dari kuesioner ini yaitu siswa SMP/Sederajat dan siswa SMA/Sederajat. Maka dilakukan kuesioner pada 22 orang siswa yang terdiri dari 8 orang siswa SMP/Sederajat, dan 14 orang siswa SMA/Sederajat. Pengguna dipersilahkan untuk mencoba aplikasi Pupuh Sunda yang dikembangkan dan juga Pupuh Sunda yang ada di Play Store.

Untuk menghitung hasil kuesioner digunakan metode Skala Likert sebagai berikut :

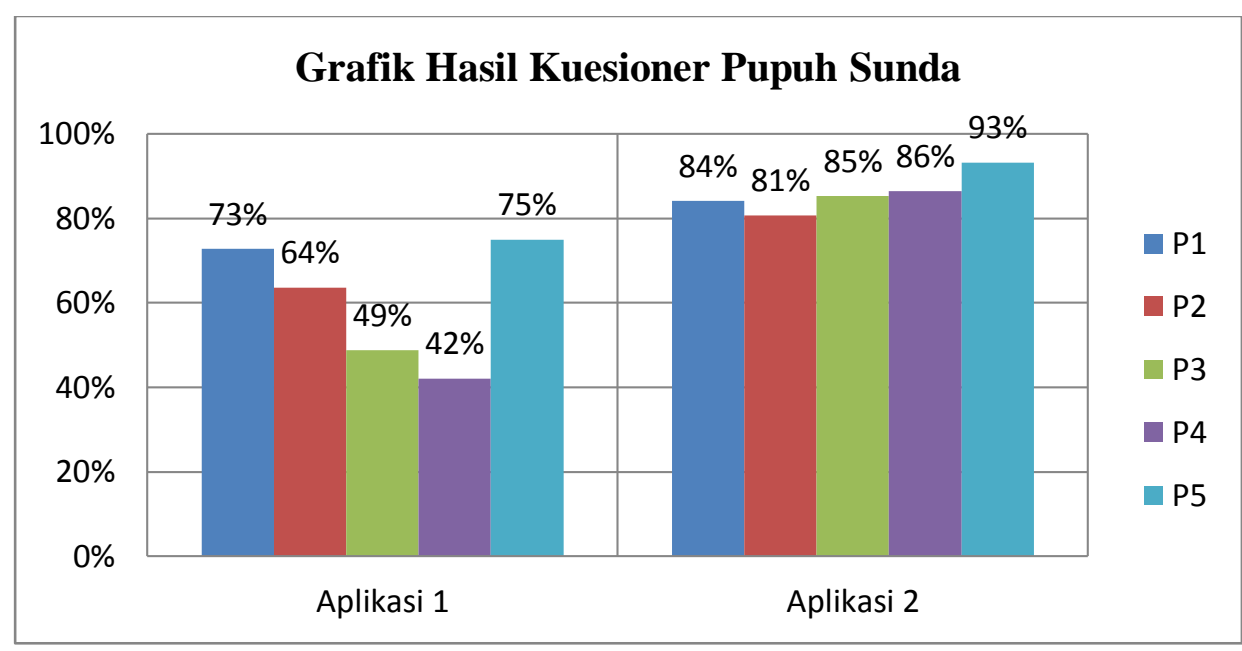

Gambar 8 Grafik Perolehan Nilai Setiap Pertanyaan

Grafik pada gambar 8 diatas menunjukan nilai-nilai yang diperoleh dari kuesioner. Pupuh Sunda 1 adalah aplikasi Pupuh Sunda yang terdapat di Play Store, sedangkan Pupuh Sunda 2 adalah aplikasi yang dikembangkan pada penelitian ini.

Setelah melakukan perhitungan poin, maka dihasilkan nilai 378 dari nilai maksimal 440 yang bisa didapatkan untuk aplikasi Pupuh Sunda yang kembangkan. Sedangkan aplikasi Pupuh Sunda yang ada di Play Store mendapatkan nilai 226 dari 440 nilai maksimum yang dapat diperoleh. Dari grafik di atas juga dapat dilihat bahwa persentase yang didapatkan oleh Pupuh Sunda 2 lebih tinggi dari Pupuh Sunda 1. Nilai interpretasi rata-rata yang didapatkan Pupuh Sunda 2 yaitu $86 \%$, lebih baik dari Pupuh Sunda 1 yang hanya memperoleh nilai interpretasi $60 \%$. Dengan hasil ini dapat dikatakan bahwa aplikasi Pupuh Sunda hasil penelitian ini lebih baik daripada aplikasi Pupuh Sunda yang terdapat di Google Play Store. 


\section{KESIMPULAN}

Setelah melakukan analisis, perancangan, implementasi, dan pengujian, maka diperoleh kesimpulan sebagai berikut :

1. Membantu melestarikan pupuh Sunda dengan cara membuat aplikasi berbasis Android dan menyebarkannya secara gratis.

2. Aplikasi Pupuh Sunda hasil penelitian ini mengalami peningkatan kualitas suara dibandingkan dengan aplikasi Pupuh Sunda versi Play Store.

3. Semua fitur yang dimiliki aplikasi Pupuh Sunda ini berjalan dengan baik. Fitur-fitur baru yang ditambahkan adalah teori tentang pupuh, kemampuan menampilkan lirik lain, dan kuis.

4. Berdasarkan kuesioner yang dilakukan kepada 22 orang siswa, dapat diketahui bahwa aplikasi Pupuh Sunda hasil penelitian ini lebih baik dari aplikasi Pupuh Sunda yang terdapat di Play Store.

\section{SARAN}

Untuk mengembangkan kembali aplikasi Pupuh Sunda ini, maka disarankan untuk dapat menambahkan fitur Kirim Saran, Update, dan juga fitur Pilih Lagu Pupuh. Penelitian selanjutnya lebih menyarankan pada fitur Pilih Lagu Pupuh karena pupuh Sunda memiliki lirik yang berbeda-beda maka fitur ini sangat membantu bagi pengguna yang ingin mengetahui lebih banyak lagu pupuh.

\section{DAFTAR PUSTAKA}

[1] M. Z. Mumuh,. 2011. Kajian Identifikasi Permasalahan Kebudayaan Sunda Masa Lalu, Masa Kini, dan Masa Yang Akan Datang. Universitas Padjadjaran, Bandung.

[2] F. Yussi Nisfi. 2012. Karakteristik Pupuh Kinanti Kawali. Universitas Negeri Yogyakarta.

[3] S. Haryono, 2014. Sastra Tembang Pada Kontekstual Adegan Damarwulan Sebagai Penguasa Majapahit Dalam Tari Langendriyan. Greget, vol. 13, no. 1, pp. 75-90.

[4] pikiran-rakyat, 2012. Generasi Muda Krisis Kebudayaan," http://www.pikiranrakyat.com/seni-budaya/2012/05/05/187282/generasi-muda-krisis-kebudayaan.

[Online]. Available: http://www.pikiran-rakyat.com/seni-budaya/2012/05/05/187282/ generasi-muda-krisis-kebudayaan. [Accessed: 23-Jul-2016].

[5] G. Ngurah Wira Satryawan, I. Gede Mahendra Darmawiguna, and I. Made Gede Sunarya. 2014. Pengembangan Media Belajar Pupuh Berbasis Android. J. Pendidik.

Teknol. dan Kejuru., vol. 11, no. 2.

[6] I. Gede Agus Maha Putra. 2015. Aplikasi Pembelajaran Nyanyian Pupuh Tradisional Bali Berbasis Android di Sekolah Dasar. Telkom University.

[7] H. Gastón, 2014. Developing Cross-Platform Mobile Apps with HTML5 and Intel XDK. Dr. Dobb's Journal.

[8] H. Al Fatta, 2007. Analisis dan Perancangan Sistem Informasi untuk Keunggulan Bersaing Perusahaan dan Organisasi Modern.

[9] P. Pudjo Widodo and Herlawati. 2011. Menggunakan UML. Bandung: Informatika.

[10] F. Noviyanto. 2012. Membangun sistem pembelajaran pengenalan bentuk untuk anak berbasis multimedia dan game interaktif," J. Inform., vol. 2, no. 1, pp. 158-167. 